\title{
Capitalizing on Early Project Opportunities to Improve Facility Life-Cycle Performance
}

\author{
by \\ Calvin Kam¹, Martin Fischer ${ }^{2}$, Reijo Hänninen ${ }^{3}$, Seppo Lehto ${ }^{4}$, Jarmo Laitinen ${ }^{5}$
}

\begin{abstract}
This paper presents the findings from the design and construction of the Helsinki University of Technology Auditorium Hall 600 (HUT-600) in Finland. Running simultaneously with the construction project, an international research partnership extensively documented and analyzed the use of product modeling and interoperability standards for information exchange. The project team improved design cycle times and minimized data re-entry through an array of design, visualization, simulation, and analysis tools. Building on the resulting efficiency and time-savings during the early conceptual phase, the project team conducted a variety of in-depth life-cycle studies and alternative comparisons on thermal performance, operation costs, energy consumption, and environmental impact. Such unconventional practices empowered the building owners to better align the long-term facility values with their strategic plans.
\end{abstract}

KEYWORDS: Life-Cycle Analysis, Pilot Project, Product Model

\subsection{INTRODUCTION}

The design and construction of the Helsinki University of Technology Auditorium Hall 600 (HUT-600) adhered to the Level of Influence on Project Costs concept (Paulson 1976) that making a decision during the early project phase has a relatively high impact and low cost. This paper explains the Product Model and $4^{\text {th }}$ Dimensional (PM4D) Approaches and PM4D Processes that were developed in the HUT-600 project. We document the life-cycle studies made during the early schematic design phase of HUT-600, highlight their relationships with PM4D Approaches and Processes, and analyze their implications on the long-term performance of the capital facility.
In autumn 2000, the Helsinki University of Technology requested its property owner, Senate Properties of Finland, to build a new multipurpose auditorium that would be capable of accommodating 600 people. Running on a fast-track design and construction schedule, Senate Properties assembled a team of designers, consultants, contractors, and researchers early during the conceptual planning phase. This partnership received financial supports from the Finnish National Technology Agency (TEKES), which sponsored the testing of state-of-the-art technologies and data standards in HUT-600. Since HUT-600 is the first institutional application of the Industry Foundation Classes

\footnotetext{
${ }^{1}$ Graduate Research Student, Civil \& Environmental Engineering, Stanford University, Stanford, CA. 94305-4020, U.S.A. <ckam@stanford.edu>

${ }^{2}$ Associate Professor, Civil \& Environmental Engineering and (by courtesy) Computer Science, Director of the Center for Integrated Facility Engineering, Stanford University, Stanford, CA. 943054020, U.S.A. <fischer@stanford.edu>

${ }^{3}$ General Manager, Olof Granlund Oy, Helsinki, Finland < reijo.hanninen@granlund.fi $>$

${ }^{4}$ Senate Properties, Helsinki, Finland <seppo.lehto@senaatti.com>

${ }^{5}$ Ph.D, Customer Solutions, Solibri Inc., Helsinki, Finland <jarmo.laitinen@solibri.com>
} 
(IFC) interoperability standards, it is also a construction pilot. 


\subsection{THE PM4D APPROACHES}

The HUT-600 project team followed the PM4D Approaches in which they relied on product modeling and interoperability standard to eliminate the inefficiency and risks of data re-entry in conventional practices. The approaches aimed at leveraging upon state-ofthe-art analytical and visualization tools to optimize the design, construction, and operation of the proposed facility during early project phases (Kam et al 2002).

The approaches recognized the importance of having cross-disciplinary expertise to improve design and construction integration. With the goal of improving the quality of design and construction services, the approaches called for utilizing intelligent object-oriented product models and the IFC interoperability standard that supported data sharing. Furthermore, the approaches adopted various visualization tools and analysis tools to additional life-cycle performance data to support the decisionmaking processes.

\subsection{THE PM4D PROCESSES}

The PM4D Processes explain the software applications, data standards, and information flow that took place in HUT-600. During the early schematic phase, the architects and mechanical engineers designed with objectoriented modeling software such as Graphisoft's ArchiCAD ${ }^{6}$ and Progman Oy's MagiCAD $^{7}$. IFC release 1.5.1 interoperability standard reduced the needs to re-enter geometric data, thermal values, and material properties (Kam et al 2002). Efficient model and data sharing during the schematic design phase allowed the building-systems consultants to simulate various cooling and heating requirements based on the architectural product model. These thermal values were directly imported to the Heating, Ventilating, and Air-Conditioning (HVAC) design application, where the mechanical consultants directed the distribution path. The software then automatically sized and balanced the mechanical components. The object-oriented

\footnotetext{
${ }^{6}$ URL: http://www.graphisoft.com

${ }^{7}$ URL: http://www.progman.fi/english/e_index.htm
}

HVAC application then exported the geometry of ducts and air handling units for the architects to incorporate into the architectural model and generated a bill of materials for the general contractor.

Synthesizing the readily available bill of materials from the mechanical consultants and the three-dimensional geometry from the architects, the general contractor for HUT-600 utilized an automated cost estimating and value engineering system, again object-oriented and IFC-compliant, to match design components with the contractor's database for cost estimation, scheduling, and resource leveling.

Compared to a conventional approach, this relatively seamless data exchange and the related automated tools tremendously expedited design time and improved the quality of interdisciplinary collaboration (Kam et al 2002). As a result, the project team quickly generated three design and two building system alternatives and was ready to take advantage of the time savings to perform further value-added work.

\subsection{LIFE-CYCLE ANALYSES}

The PM4D Approaches and PM4D Processes called for an enhancement of the facility performance over its total life span. Hence, HUT-600's project team conducted a series of life-cycle analysis to evaluate the thermal performance, cost implications, and environmental impacts of project alternatives.

In the following subsections, we explain how the project team evaluated two air-conditioning system alternatives - mixed cooling versus displaced cooling systems. In mixed cooling, the system supplies high velocity cold air from the ceiling. It is simpler in design and cheaper in cost when compared to a displaced cooling system, which slowly cools the space from the floor and displaces the warm air up to the exhaust in the ceiling.

\subsection{Thermal Performance}


The mechanical engineers utilized Olof Granlund Oy's $^{8}$ RIUSKA ${ }^{9}$ for thermal simulations and AEA Technology's CFX ${ }^{10}$ to conduct computational fluid dynamics (CFD) analyses. Since the auditorium space was a critical room with heat emission from 600 users and more than 200 light fixtures, RIUSKA's predictions and CFX's analyses enabled the engineers to quantitatively compare the profiles of temperature and air velocity stratification between the mixed and the displaced cooling schemes.

RIUSKA accounted for the dynamic behavior of thermal masses in response to the changing exterior temperatures through an hourly increment over a 12-month period. Thus, engineers could combine different spaces and building systems to test various insulation and construction assembly options. Once the indoor air temperature target was specified, the program took a few minutes to analyze the thermal loads from the occupancy, the occupants' schedule, the equipment, and the exterior temperature conditions against the different insulation schemes, window transmittance, and louver systems.

Taking RIUSKA's analysis results as its target range and boundary conditions, CFX took about 10 hours to iteratively solve for the finite numeric values of air temperature and supply air velocity across the sectional profiles of the auditorium space. The CFX results illustrated that in spite of a supply of lower air temperature of 17 degree Celsius, the mixed cooling system was not as efficient as the displaced cooling system (required supply air temperature of 19 degree Celsius) in the occupants' zone - the area that mattered most. Hence, the engineers learned from numerical values and vivid graphical profiles (see Figure 1) that the mixed system had to supply cooler air at higher velocity in order to balance the warmer air around the lighting fixtures in the ceiling level.

\subsection{Cost Analysis}

\footnotetext{
${ }^{8}$ URL: http://www.granlund.fi/English/runko.htm

${ }^{9}$ URL: http://www.eren.doe.gov/buildings/tools_ directory/software/riuska.htm

${ }^{10}$ URL: http://www.software.aeat.com/cfx
}

The HUT-600 project consultants employed Olof Granlund Oy's BSLCC software to project the operation and maintenance costs of project alternatives throughout the facility's expected life-span. The consultants and the construction managers shared their respective knowledge from past projects, facility management data, and the manufacturers' catalogues to estimate energy consumption costs, maintenance costs, and immediate investment costs (see Figure 2), which all together provided reliable quantitative decision supports for selecting mechanical system, choosing electrical lighting and maintenance methods, and qualifying bid packages from air handling unit manufacturers.

In the mixed versus displaced cooling analysis, HUT-600 consultants assumed the systems had a 50-year service life span. For both alternatives, BSLCC read the automatically generated bill of materials from the objectoriented applications, estimated the cost of initial investment, and projected operation cost based on energy consumption and system efficiency. With the analysis tool, the consultants also accounted for the maintenance cost, replacement cost, financing cost, as well as inflation cost. The in-depth comparison results informed the decision makers that the equivalent annual cost of the displaced airconditioning system was $6 \%$ higher than that of the mixed air-conditioning system.

\subsection{Environmental Impact Analysis}

With Olof Granlund Oy's BSLCA software, the building system consultants conducted environmental impact assessments to evaluate the environmental influences of the building materials and the estimated energy consumed by the facility. In particular, the consultants extracted the material properties and quantity information from the product model of the alternative designs. They deduced the level of environmental impacts to air and water and subsequently, they quantified the amount of pollution emission, global warming, acidification, etc. in support for material and system comparison (see Figure 3). 
Iteratively, the designers, consultants, and construction managers evaluated and counterproposed materials, structural systems, and building systems among themselves to balance aesthetics, performance, cost, and environmental impacts during the project design phase.

\subsection{IMPLICATIONS}

Kam et al (2002) reported that in HUT-600 the use of object-oriented product models and interoperability standard resulted in about 50\% time savings in design documentation, as a result of object-oriented library, parametric properties, knowledge reuse, and data sharing. PM4D Approaches and PM4D Processes expedited the traditional schematic design services. As a result, the project team shifted their attention from performing routine jobs to conducting life-cycle analyses. Such analyses added project values while reducing the risks of cost overrun or dissatisfaction of long-term performance.

Had the HUT-600 project team not conducted life-cycle analyses on mixed versus displaced cooling systems, risk-adverse decision-makers would probably select the mixed system rather than the displaced cooling system. Since the latter system required an expensive under-floor distribution system, the lack of its performance evidences and operating cost information projection would have posted skepticisms to decision makers. While in HUT-600, not only did PM4D Approaches and analysis tools ensure the early availability of life-cycle analyses, they also improved the quality of the decision factors. For instance, the dynamic thermal behaviors that RIUSKA analyzed for the thermal performance are usually approximated or omitted in conventional design approaches.

HUT-600 consultants noted, and conferred by the project construction managers, that in the total spending on a capital facility, $80 \%$ of the total cost is spent on the operation and maintenance, whereas the remaining $20 \%$ goes to planning, design, and construction. Hence, it is crucial to capitalize on early project opportunities to optimize the facility design for long-term performance.

By March 2001, only three months into the design phase, the abovementioned analytical results were available to the owner and the project team members. Subsequently, the owners evaluated various project alternatives (e.g., architectural features, mixed versus displaced cooling systems, etc.) based on their functional performance, projected operating costs, maintenance costs, and environmental impacts and chose the most efficient designs and systems that best met their long term strategic goals. In the selection of airconditioning system, the owners were confident to invest in the more energy efficient, environment-friendly, slightly more expensive, and better performance systemthe displaced cooling system.

Furthermore, the HUT-600 project team also explored various visualization tools, such as virtual reality-EVE ${ }^{11}, 4 \mathrm{D} \mathrm{CAD}^{12}$, virtual animations, etc., to foster early and effective communications among the end-users, owners, and project team.

While all the HUT-600 project stakeholders enjoyed the benefits that we documented in this paper, there were still barriers and wishlist items that could have further improved the design services and better expedited the data sharing process. Such wish-list items included simpler data conversion processes, stronger interoperability, and better supports for revision handling (Kam et al 2002).

\subsection{CONCLUSION}

Shared among the owners, project team, and research partner of HUT-600 was a committed belief in capitalizing on early project opportunities to make a lasting and positive effect on the facility over its total life-span. Leveraging upon the reduced design time and improved data exchanges, enabled by the PM4D Approaches and Processes, HUT-600's project team was able to complete a series of life-cycle studies within the original design

\footnotetext{
${ }^{11}$ URL: http://www.tml.hut.fi/Research/HUTVE

${ }^{12}$ URL: http://www.commonpointinc.com
} 
schedule. Pertinent decision factors and project alternatives were available during the early schematic design phase when making a decision had a relatively high impact and low cost.

In the nutshell, modern technologies are capable of expediting conventional design practices and promoting life-cycle approaches. Project experiences from HUT-600 construction pilot demonstrated that owners are empowered to choose among comprehensive life-cycle alternatives and to align the long-term facility values with their strategic plans, whereas project team members could differentiate themselves from their competitors with higher efficiency, better quality, and more effective application of their expertise.

\subsection{REFERENCES}

Kam, C. and Fischer, M. (2001). "Experiences from HUT-600 Auditorium Project." Presentation at VERA Seminar, Helsinki, Finland, November 20.

Kam, C.; Fischer, M.; Kunz, J.; Hänninen, R.; Lehto, S.; and Laitinen, J. (2002). "PM4D Final Report" Working Paper, Center for Integrated Facility Engineering, Stanford University, Stanford, CA, in press.

Paulson, B. (1976). "Designing to Reduce Construction Costs." Journal of the Construction Division, ASCE, Vol. 102, No. CO4, Proc. Paper 12600, December, pp. 587592. 

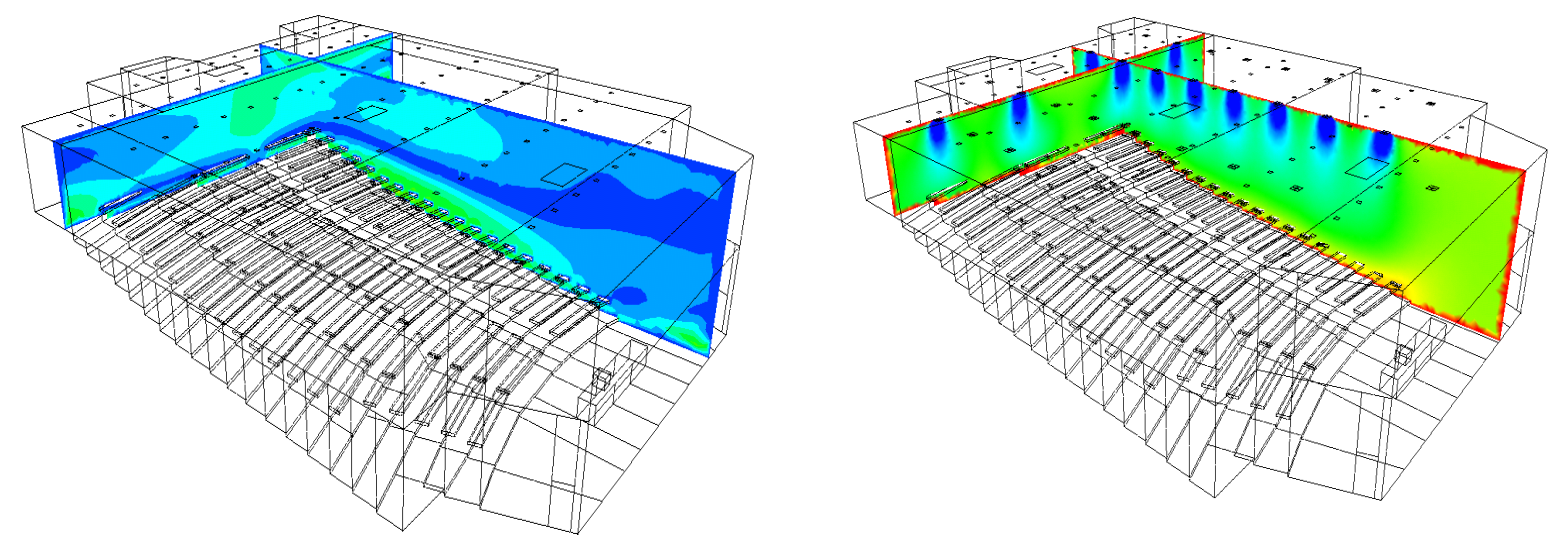

Figure 1. CFX provided CFD cross-sectional profiles of air velocity, which scales from $0.02 \mathrm{~m} / \mathrm{s}$ (blue) to $0.20 \mathrm{~m} / \mathrm{s}$ (red), in the displaced cooling scenario (Left) as well as the mixed cooling scenario (Right).
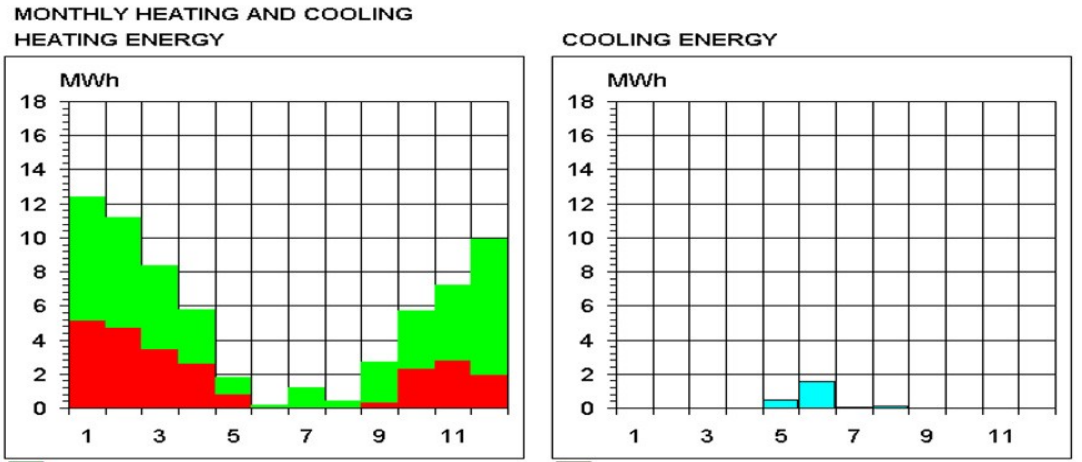

HEATING OF ROOM BY AIR

DOMESTIC WATER HEATING

COOLING OF ROOM EQUIPMENTS

COOLING OF SUPPLY AIR

Figure 2. RIUSKA projected the annual heating and cooling energy consumption for HUT-600.
Level:
Property
Life Cycle Period, 50
Case 1:
Case 2:
Displacement ventilation (supply air from flo
Mixing ventilation (supply air from ceiling)

EMISSIONS TO AIR

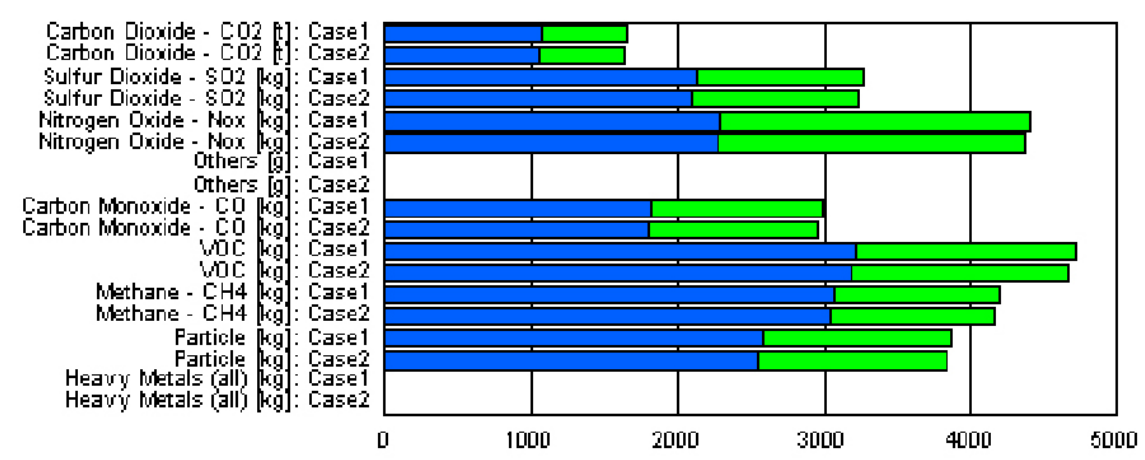

Figure 3. Charts from an environmental impact analysis showing the weight of emission (units in yaxis brackets) from energy consumption (blue) and the building materials (green) over a 50 year period in HUT-600. 